\title{
Adherence to and acceptability of home fortification with vitamins and minerals in children aged 6 to 23 months: a systematic review
}

Samara Fernandes de Barros and Marly Augusto Cardoso*

\begin{abstract}
Background: Vitamin and mineral deficiencies affect more than two million people worldwide. In 2011, based on recent scientific evidence and the low effectiveness of current strategies, the World Health Organization recommended home fortification of foods with multiple micronutrients in powder (MNP) as a new strategy to prevent and control anaemia during childhood. This systematic review assessed adherence to and acceptability of home fortification with multiple micronutrients in powder (MNP) in complementary feeding.
\end{abstract}

Methods: Adherence was assessed based on number or percentage of prescribed sachets that were consumed, and acceptability was assessed according to perceptions of caregivers and children about MNP.

Results: In summary, the studies indicated that home fortification with MNP has good adherence, ranging from $50 \%$ to over $90 \%$ of the prescribed sachets and that MNP was well accepted by caregivers. Caregivers reported side effects in $3 \%$ to $32 \%$ of children taking MNP in many studies; diarrhoea, vomiting, and constipation were the most common.

Conclusions: Home fortification with MNP has good adherence and acceptability in infants, with higher adherence in non-daily or flexible administration regimens. Characteristics of the target population and increased diarrhoea burden should be considered for planning public health programs with long term use of MNP. Acceptability of the MNP is satisfactory, when the use and perceived beneficial effects on children's health are considered.

Keywords: Multiple micronutrients in powder, Complementary feeding, Home fortification

\section{Background}

Vitamin and mineral deficiencies affect more than two million people worldwide [1]. Young children are highly vulnerable because their high nutrient requirements need to be achieved through diet, which is sometimes inadequate in quantity and quality of nutrients, especially in developing countries.

Iron deficiency anaemia is the most common preventable nutritional problem among young children, affecting more than 750 million children worldwide [2]. According to the World Health Organization, the prevalence of iron deficiency among young children is 2.5 times

\footnotetext{
* Correspondence: marlyac@usp.br

Department of Nutrition, School of Public Health, University of São Paulo,

Avenida Dr. Arnaldo 715, São Paulo, SP 01246-904, Brazil
}

the prevalence of anaemia [3]. In 2011, based on recent scientific evidence and the low effectiveness of current strategies, the World Health Organization recommended home fortification of foods with multiple micronutrients in powder (MNP) as a new strategy to prevent and control anaemia during childhood [4]. Several formulations with different compositions of micronutrients are available for use in complementary feeding. For example, Sprinkles is the most used MNP and its formulation of micronutrients was first developed in 1996 by researchers at the Children's Hospital in Toronto, to prevent micronutrient deficiencies in children [5].

Previous studies have described the efficacy of home fortification with MNP in different contexts, especially in low-income countries, where nutritional deficiencies 
in childhood are more prevalent. Most of these studies used increased average haemoglobin concentration as the main study outcome. However, few studies have evaluated adherence and acceptability, and when this information is available, adherence was assessed mainly by the number of sachets used. A recent systematic review of the effectiveness of MNP interventions found high acceptability with variable adherence, indicating that high acceptability does not always translate into adherence [1]. Adherence in trials has been defined as the extent to which a patient follows advice regarding the use of a supplement, for example. Studies have found that high adherence with fortified complementary foods has often been reflected in improved nutritional status, suggesting that adherence is a key factor in determining the effectiveness of the fortification strategy for MNP interventions $[5,6]$.

It is known that adherence and acceptability are key factors in the success of an intervention. Thus, this systematic review aimed to summarize the scientific literature examining the adherence to and acceptability of home fortification with MNP in complementary feeding for planning and evaluation of public health programs to prevent childhood anemia.

\section{Methods}

We performed a systematic review of the scientific literature in December 2013, searching for indexed published articles in the electronic databases of the U.S. National Library of Medicine and the National Institutes of Health (PubMed), the Latin American and Caribbean Literature on Health Sciences (LILACS), the Scientific Electronic Library Online (SciELO), and Thomson Reuters IP \& Science (Web of Knowledge).

The descriptors used to select articles were "micronutrients powder" OR "home fortification" OR "Sprinkles." Truncation symbols were used with the searched terms in Spanish and English to find words with the same root, increasing the chances of detecting a greater number of items. The selection of papers was restricted to articles published from 2003 to 2014 and written in Portuguese, Spanish, or English. The reference lists and some potentially relevant articles cited were examined and read to find additional articles or important information to the review.

The main eligibility criteria for selection of the published studies included a focus on children aged 6 months to 2 years or more and available information on adherence to and/or acceptability of home fortification of complementary feeding with MNP. Studies with either qualitative and/or quantitative methods were accepted.

Studies that used multiple micronutrients not in powder form, articles with target populations not in the age range of interest, abstracts or Congress Annals, other review articles, and technical reports were excluded for the purpose of this review.
The identification and selection of the articles were performed by two authors independently. Studies were initially selected based on their titles, and these were included in the next step of reading abstracts. Articles selected based on their abstracts were then read in full before the final selection decision, based on the criteria listed above. Discrepancies were resolved by the two authors.

A flowchart for processing and data analysis was organized to describe the steps in paper selection (Fig. 1). After all papers were read, a spreadsheet was created in Microsoft Excel 2010 to extract the relevant information from each study. Virtual Endnote Web software was used to assist in organizing the articles and writing this manuscript. Finally, descriptive tables were created with a synthesis of included articles, listing the following information: author, publication year, country, prevalence of nutritional disorders, study aim, population and design, intervention characteristics and results regarding adherence, acceptability, and side effects of home fortification with multiple micronutrients. Considering the scope of this review with a focus on available data on adherence to and acceptability for the use of MNP in complementary feeding, we did not follow strict criteria for assessing quality of the revised articles. In this review, adherence was defined as a quantitative measure of the number of sachets used compared with the expected use over a specified time frame informed in the revised studies; acceptability was considered as a subjective measure related to caregivers perceptions of the child's acceptance of the sachet, as well as perceptions of associated health benefits or side effects.

\section{Results}

Overall, 131 references were found using our search criteria. Most articles were excluded after reading their titles and abstracts based on the exclusion criteria, leaving only 19 articles eligible for full reading. Of these, two were excluded because they did not provide information on adherence to and acceptability of home fortification. The remaining 17 articles that met the inclusion criteria were selected for detailed analysis of adherence to and acceptability of home fortification with MNP in complementary feeding (Fig. 1).

Tables 1 and 2 shows the main characteristics of the selected 14 clinical trials and three observational studies, respectively. Most of these studies were conducted in low-income countries: two in South America [7, 8], one in Central America [9], three in North America [10-12], eight in Asia [13-20], and three in Africa [21-23].

A high prevalence of anaemia and stunting was found in children less than 2 years of age at analysed sites. The sample size in these studies ranged from 47 to 2,746 children and the duration of intervention ranged from 1 


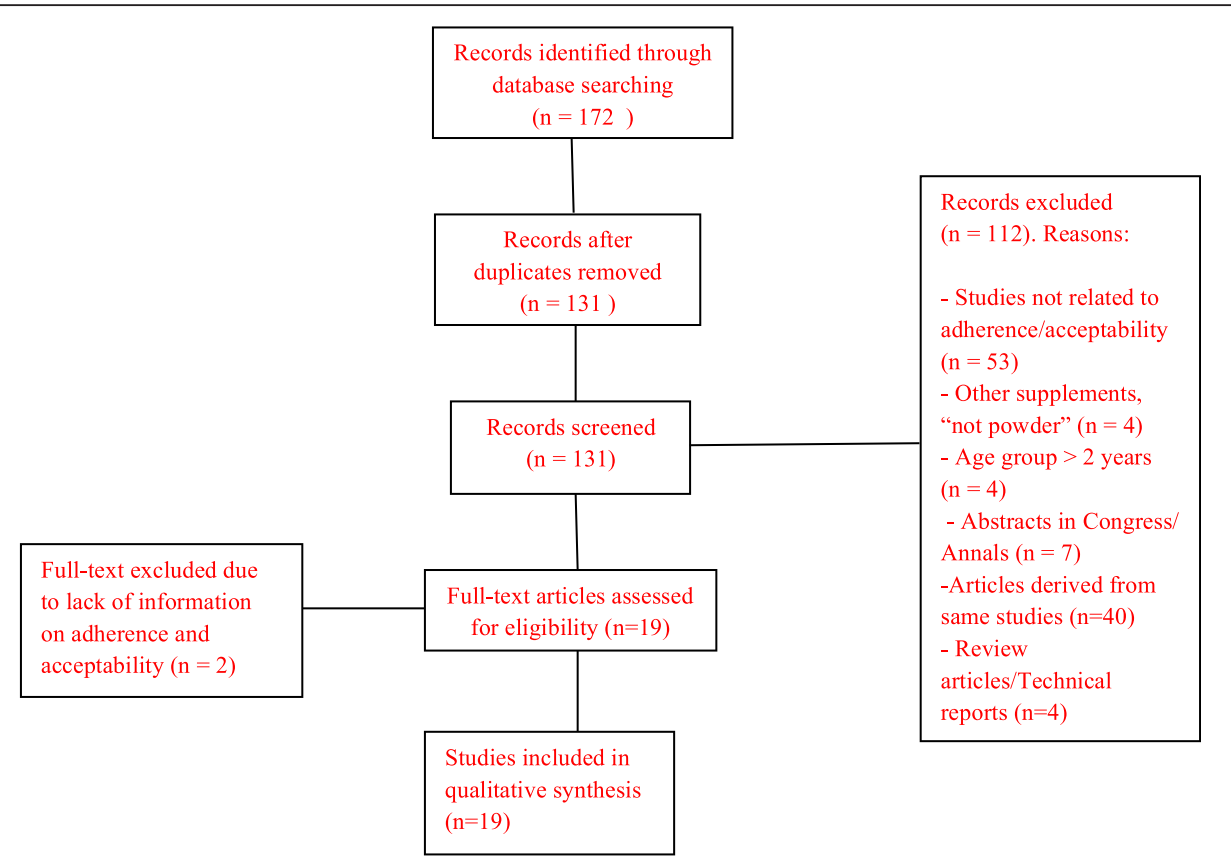

Fig. 1 Flowchart of article selection

to 26 months, with a 6-month intervention in six studies $[8,10,1317,18,21]$. Twelve studies offered MNP to children daily $[7,9-12,15,17,19-23]$, three adopted non-daily administration, five or fewer sachets per week $[8,13,14]$ and two articles compared daily with nondaily administration $[16,18]$. In addition, five studies compared MNP with other supplement types or fortified foods $[9,11,12,21,23]$ and two studies compared different MNP formulations [7, 20].

In all reviewed studies caregivers received instructions about appropriate use of the MNP sachets. One package of MNP should be added in a small portion of usual semi-solid food to be consumed fully for the child. Only in study conducted by Sampaio et al. MNP sachets were administered out of home, in childcare centre. The authors commented that the banana was the food commonly used to mix MNP sachets; in remaining studies no information on this was provided [7].

Table 3 summarizes the information collected on adherence to and acceptability of home fortification with MNP in young children. Reviewed studies assessed adherence based on number or percentage of prescribed sachets that were consumed. Acceptability was assessed according to perceptions of caregivers and children about MNP. For example, the reasons for children or caregivers like or dislike of MNP, such as taste, flavor, ease of use, ease of transportability, health benefits and others.

\section{Adherence and acceptability}

Eight studies reported an average consumption of sachets ranging from $50 \%$ to $96 \%$ of the recommended number $[7,9,10,17,19-22]$. Only one study reported unsatisfactory adherence to MNP administration. Those authors considered consumption of five to seven sachets per week to be high adherence, and this number was achieved by $31-46 \%$ of participants in the study [11].

In the two papers that assessed adherence to consumption of sachets in a daily versus a non-daily scheme, the authors found higher rates of adherence in non-daily regimes, and in these groups the average consumption was greater than $90 \%$ of the prescribed sachets $[16,18]$.

In general, MNP were well accepted by caregivers and by children. Among the mentioned factors that contributed to high acceptability were transportability, ease of preparation and use, perceived benefits to children's health (increased appetite and agility), and preservation of the organoleptic characteristics of the children's meals. Nevertheless, some studies reported that MNP caused changes in the colour or taste of food, including yellowing of rice, bitterness of food after mixing with MNP, and the unpleasant taste of MNP itself. In most of these studies, the authors did not report whether the MNP had been consumed with liquids, such as broth soups or fruit juices $[12,14,15,18]$.

Most mothers expressed interest in continuing MNP use and recommended MNP to other mothers, if these products were available in their regions. In the study by Rosado et al. 2010 MNP had lower acceptability than other supplements used in the study (iron supplement, iron and folic acid supplement, micronutrient-fortified complementary food or zinc/iron/ascorbic acid fortified 
Table 1 Clinical trials assessing adherence to and acceptability of home fortification with multiple micronutrients in powder (MNP) in complementary feeding

Inayati et al. Nias Island, $\quad$ Stunting $=34.1 \%$; anaemia $=$ (2012) [15] Indonesia $51.7 \%$.

Sampaio et al. Bahia, Brazil (2012) [7]

Avula et al. Rajasthan, India Stunting $=48.0 \%$ in India. (2011) [13]

\section{Kounnavong Rural}

[18] Democratic Anaemia $=63.5 \%$

Republic

Tripp et al. Niger $\quad$ Stunting $=49.0 \%$; Anaemia $=$

(2011) [23]
Stunting $=5.3 \%$ and $7.4 \%$, respectively, in intervention and control groups.

$91.0 \%$.

Study design

To assess the effects of provision of Cluster-randomized trial.

Three groups: non-supplemented

control, MNP without zinc

without zinc, on children's growth, control, MNP without zinc,
micronutrient status, and morbidity. and MNP with $10 \mathrm{mg}$ of zinc

To evaluate the effect of MNP

alongside infant and young child

feeding education program

compared with feeding education alone on anaemia, iron deficiency, vitamin A, zinc, and growth in

Cambodian infants.

To assess the impact of intensive nutrition education with or without the provision of MNP on the nutritional status of mildly wasted children.

To evaluate the incidence of diarrheal disease and acute respiratory infection in children undergoing supplementation with zinc and other micronutrients through the use of MNP.

To assess the impact of the existing Supplemental Nutrition Program with local production of supplemental food, home fortification with MNP, and monitoring.

To compare the effect of twice weekly versus daily supplementatio with MNP on anaemia prevalence, haemoglobin concentration, and growth in infants and young children.

To assess the acceptability of an MNP and a lipid-based nutrient supplement (Nutributter), and to explore people's willingness to pay for these products.

Cluster-randomized effectiveness trial.

Two groups: non-supplemented control received infant and young child feeding education alone alongside education. supplemented MNP plus monthly non-intensive nutrition education program; non-intensive education program alone.

Randomized clinical trial, double blind.

Two groups: supplemented contro group supplemented with MNP with zinc.

Quasi-experimental.Two groups: control group received the usual intervention group received the enhanced program.

supplementation.

Qualitative study. MNP or Nutributter for 4 weeks; 2.

Supplemented with MNP and Nutributter for 2 weeks each. supplemented group received MNP

Cluster-randomized trial.Four groups: $n=215$ MNP plus intensive education; children, aged intensive nutritional education alone; 6 to with MNP without zinc; intervention Supplementation Nutrition Program;

Randomized trial.Three groups: nonsupplemented control, twice weekly supplementation, and daily

Two groups: 1. Supplemented with children, aged 6 to

52 months. Intervention duration: 24 weeks Total sachets prescribed: 168 (daily group) or 48 (twice weekly) Iron dosage in MNP: $10 \mathrm{mg}$

Frequency: daily

Intervention duration: 1 yea (or until child reached a Iron dosage in MNP: $10 \mathrm{mg}$

$n=143 \quad$ Frequency: daily

children, aged Intervention duration: 90 days 6 to Total sachets prescribed: 90 Iron dosage in MNP: $12.5 \mathrm{mg}$

$n=1128 \quad$ Frequency: five times weekly children, aged Intervention duration: 6 months 6 to $\quad$ Total sachets prescribed: $\approx 120$ 30 months. Iron dosage in MNP: $12 \mathrm{mg}$

$n=83$ children, Frequency: daily

aged 6 to Intervention duration: 4 weeks 23 months. Total sachets prescribed: 28 or 14 Iron dosage in MNP: 6 mg weight-for-height $z$ score $\geq-1$ ) 
Table 1 Clinical trials assessing adherence to and acceptability of home fortification with multiple micronutrients in powder (MNP) in complementary feeding (Continued)

Geltman et al. United States Iron deficiency $=15.0-35.0 \%$. (2009) [11]

\begin{tabular}{|c|c|c|}
\hline $\begin{array}{l}\text { Adu- } \\
\text { Afarwuah et } \\
\text { al. (2008) [21] }\end{array}$ & Ghana & $\begin{array}{l}\text { Anaemia }=23.0-30.0 \% \text { in both } \\
\text { groups. }\end{array}$ \\
\hline
\end{tabular}

Ip et al. (2007) Bangladesh $[16]$

Menon et al. Haiti (2007) [9]

Anaemia $=52.0 \%$ and $37.0 \%$ in groups 1 and 2, respectively.

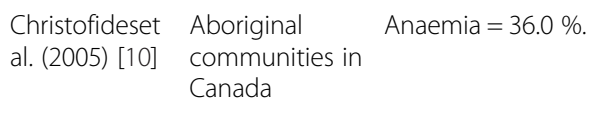
Anaemia $=75.8 \%, 81.7 \%$ $73.0 \%$, in daily for 2 months,

To test the effectiveness of a
2-month intervention with daily
home fortification of complementary
food using MNP in reducing
anaemia among children 6 to
36 months of age.
To evaluate the efficacy and
children's acceptance of several
recognized strategies to treat
anaemia.
anaemia.

To determine whether low-income infants' adherence to MNP was

better than to ferrous sulfate drops.

To compare the efficacy and

acceptability of MNP, Nutritabs, and fat-based Nutributter, which provide 6,16 , and 19 vitamins and minerals, respectively, when used for home fortification of complementary foods.

To compare the effects of daily versus flexible administration of MNP flexible for 3 months, and flexible for 4 months groups, respectively. adherence, acceptability, and children in rural Bangladesh.

To evaluate the effectiveness of 2-months treatment with MNP in reducing anaemia among children 9-24 months.

To determine the acceptability and safety of MNP as a strategy for delivering iron to infants and young children

Cluster-randomized trial.

Two groups: non-supplemented

control and intervention

supplemented with multiple

$=2193$

children, 6 to

36 months. Frequency: daily

micronutrients.

Randomized clinical trial.Five groups: 1. Iron supplement, 2. Iron + folic

acid supplement, 3. MNP, 4.

$n=266$

children, aged Intervention duration: 4 months

43 months Total sachets prescribed: 120

tary food as porridge powder, and 5 .

Zinc + iron + ascorbic acid-fortified

water.

Randomized clinical trial.

Two groups: Supplemented with

$\begin{array}{ll}n=150 & \text { Frequency: daily } \\ \text { children, aged } & \text { Intervention duration: } 3 \text { months }\end{array}$

MNP, supplemented with iron syrup. 6 months.

Randomized trial.

Four groups: non-supplemented

supplemented with MNP;

supplemented with Nutritabs;

supplemented with Nutributter

\section{Cluster-randomized trial}

Three groups: supplemented daily with MNP for 2 months;

supplemented with MNP with a

flexible regimen for 3 months;

supplemented with MNP with a

flexible regimen for 4 months.

Cluster-randomized pre-post

intervention trial.

Two groups: group 1 supplemented with MNP plus fortified food; group 2 supplemented with fortified food alone.

Double-blinded randomized

controlled trial.

Two groups: control; supplemented with MNP.

Total sachets prescribed: 90

Iron dosage in MNP: $12.5 \mathrm{mg}$

Iron dosage in ferrous sulphate
drops: $10 \mathrm{mg}$ of elemental iron

$\begin{array}{ll}n=313 & \text { Frequency: daily } \\ \text { children, aged } & \text { Intervention duration: } 6 \text { month }\end{array}$

Frequency: daily

6 months. Total sachets prescribed: 180 Iron dosage in MNP: $12.5 \mathrm{mg}$

$n=36$

Frequency: Depended on the

children, aged treatment regimen. The children

6 to received 60 sachets each.

24 months. Intervention duration: 2, 3, or

4 months.

Total sachets prescribed: 60

Iron dosage in MNP: $12.5 \mathrm{mg}$

$n=41$ children, Frequency: daily

aged 9 to Intervention duration: 2 months

aged 9 to

Total sachets prescribed: 60 Iron dosage in MNP: $12.5 \mathrm{mg}$

$n=102 \quad$ Frequency: daily

children, aged Intervention duration: 6 months

4 to Total sachets prescribed: 180

18 months. Iron dosage in MNP: $30 \mathrm{mg}$ 
Table 2 Observational studies assessing adherence to and acceptability of home fortification with multiple micronutrients in powder (MNP) in complementary feeding

\begin{tabular}{|c|c|c|c|c|c|c|}
\hline $\begin{array}{l}\text { Source } \\
\text { study }(n=3)\end{array}$ & Site & $\begin{array}{l}\text { Prevalence of } \\
\text { nutritional } \\
\text { disorders }\end{array}$ & Study aim & Study design & $\begin{array}{l}\text { Sample at } \\
\text { baseline }\end{array}$ & Intervention \\
\hline $\begin{array}{l}\text { Espino et al. } \\
\text { (2012) [8] }\end{array}$ & $\begin{array}{l}\text { Apurímac, } \\
\text { Peru }\end{array}$ & Anaemia $=64.0 \%$ & $\begin{array}{l}\text { To evaluate the } \\
\text { implementation of the } \\
\text { program of universal } \\
\text { supplementation with MNP } \\
\text { "chispitas" through the } \\
\text { quantity and quality of } \\
\text { sachets consumed and its } \\
\text { relation to anaemia. }\end{array}$ & $\begin{array}{l}\text { Cluster-randomized trial. } \\
\text { One group: } \\
\text { supplemented with } \\
\text { MNP }\end{array}$ & $\begin{array}{l}n=714 \\
\text { children, } \\
\text { aged } 6 \text { to } \\
35 \text { months. }\end{array}$ & $\begin{array}{l}\text { Frequency: at least } 15 \text { sachets } \\
\text { monthly } \\
\text { Intervention duration: } 6 \text { months } \\
\text { Total sachets prescribed: } 90 \\
\text { Iron dosage in MNP: } 12.5 \mathrm{mg}\end{array}$ \\
\hline $\begin{array}{l}\text { Bilukha et } \\
\text { al. (2011) } \\
{[14]}\end{array}$ & Butan & $\begin{array}{l}\text { Stunting }=39.2 \% ; \\
\text { anemia }=43.3 \%\end{array}$ & $\begin{array}{l}\text { To evaluate the } \\
\text { effectiveness of a program } \\
\text { to distribute MNP on a } \\
\text { large scale in reducing the } \\
\text { prevalence of anaemia and } \\
\text { monitoring morbidity and } \\
\text { growth in refugee children. }\end{array}$ & $\begin{array}{l}\text { Longitudinal cluster- } \\
\text { randomized trial. } \\
\text { One group: supplemented } \\
\text { with MNP (no control } \\
\text { group). }\end{array}$ & $\begin{array}{l}n=502 \\
\text { children, } \\
\text { aged } 6 \text { to } \\
59 \text { months. }\end{array}$ & $\begin{array}{l}\text { Frequency: } 15 \text { sachets monthly } \\
\text { Intervention duration: } 26 \text { months } \\
\text { Total sachets prescribed: } 390 \\
\text { Iron dosage in MNP: } 10 \mathrm{mg}\end{array}$ \\
\hline $\begin{array}{l}\text { Jefferds et } \\
\text { al. (2010) } \\
{[22]}\end{array}$ & Kenya & No data given. & $\begin{array}{l}\text { To describe community } \\
\text { members' reactions to and } \\
\text { experiences using MNP, } \\
\text { with an emphasis on } \\
\text { acceptability, utilization, } \\
\text { and promotion. }\end{array}$ & Qualitative study. & $\begin{array}{l}n=47 \\
\text { children, } \\
\text { aged } 6 \text { to } \\
59 \text { months. }\end{array}$ & $\begin{array}{l}\text { Frequency: daily } \\
\text { Intervention duration: } 1 \text { month } \\
\text { Total sachets prescribed: } 30 \\
\text { Iron dosage in MNP: } 12.5 \mathrm{mg}\end{array}$ \\
\hline
\end{tabular}

water). According to the authors, most cases of rejection resulted from the taste of the MNP, probably because of their mineral concentrations [12].

\section{Side effects}

The most commonly reported side effects in these studies were diarrhoea, vomiting, and constipation, ranging from $3 \%$ to $32 \%$ of participants.

Changes in the colour of stools were seen in $95 \%$ of participants in the study by Lundeen et al.; however, this is a harmless expected effect of iron supplementation. These authors did not comment on whether differences in adherence were associated with the occurrence of side effects [19].

\section{Discussion}

This systematic review gathered seventeen papers and analysed the main conclusions from their results. Firstly, home fortification with MNP has good adherence in regards to the percentage of sachets consumed, with higher adherence in non-daily administration regimens. Secondly, acceptability of the MNP is satisfactory, when the use and perceived beneficial effects on children's health are considered. However, limitations persist such as limited knowledge and experience of professionals and caregivers in the use of MNP, the resolution of which could increase MNP's acceptability. Finally, MNP side effects ranged from $3 \%$ to $32 \%$ of participants, and in general posed a low risk to health.

Higher adherence in flexible administration regimens compared to daily administration can be attributed to mothers' difficulty in remembering to offer sachets daily and the possibility that mothers discontinued administration when sachets were forgotten [10].

Adherence to non-daily regimens reached $100 \%$ (all children consumed $100 \%$ of prescribed MNP sachets) in the study conducted by Kounnavong et al. [18]; however, a comparison of the impact of non-daily administration versus daily administration on levels of haemoglobin and other biochemical markers would clarify the risks and benefits of different administration frequencies.

Two studies included in this review have made this comparison [16, 18]. In the first, the authors concluded that in children with moderate to severe anaemia, daily administration more effectively increases haemoglobin concentration and reduces anaemia [18]. The second study found that haemoglobin levels at the end of the intervention were higher in the non-daily regimes, with a greater reduction in the prevalence of anaemia and a higher percentage of children who remained nonanaemic [16].

Other studies in the literature have also made this comparison $[24,25]$ and concluded that providing MNP weekly with $30 \mathrm{mg}$ of elemental iron produced haematological effects similar to daily administration with $12.5 \mathrm{mg}$ of elemental iron in anaemic children from 6 to 23 months of age [24] as well as in nonanaemic school-age children [25].

More studies are necessary for comparing risks and benefits of different administration frequencies of MNP sachets. However evidences in this review lead us to suggest that public policies and programs with no anaemic 
Table 3 Summary of results regarding adherence to and acceptability and side effects of home fortification with multiple micronutrients in powder (MNP)

\begin{tabular}{|c|c|c|}
\hline $\begin{array}{l}\text { Source study } \\
(n=17)\end{array}$ & $\begin{array}{l}\text { Adherence (or percentage of use) } \\
\text { and acceptability }\end{array}$ & Side effects and/or limitations \\
\hline Soofi et al. (2013) [20] & $\begin{array}{l}\text { Adherence: The mean number of micronutrient powder sachets } \\
\text { consumed each month was } 16.8 \text { (SD 11.7) in the MNP without } \\
\text { zinc group and } 15.2(11.9) \text { in the MNP with zinc group. } \\
\text { Acceptability: No data given. }\end{array}$ & $\begin{array}{l}\text { Side effects: Increased proportion of days with } \\
\text { diarrhoea in MNP without zinc group } \\
\text { (OR 1.15; } 95 \% \mathrm{Cl} 1.00-1.33 \text { ) and in MNP with } \\
\text { zinc group (OR 1.31; } 95 \% \mathrm{Cl} 1.13-1.51 \text { ), } \\
p=0.001 . \text { Increased incidence of bloody } \\
\text { diarrhoea in MNP without zinc group } \\
\text { (IRR 1.63; } 95 \% \mathrm{Cl} 1.12-2.39 \text { ) and in MNP with } \\
\text { zinc group (IRR } 1.88 ; 95 \% \mathrm{Cl} 1.29-2.74) \text {, } \\
p=0.003 \text {. }\end{array}$ \\
\hline
\end{tabular}

Espino et al. (2012) [8] Adherence: $5.4 \%$ of children did not receive the intervention; $60.3 \%$ consumed 60 or more sachets and only $49.0 \%$ consumed them adequately (sachets consumed fully and with semisolid food). Acceptability: Among those who received the intervention, $4.5 \%$ reported that they stopped giving sachets to children (of these, $70.0 \%$ of the children not want to eat food with sachets) and $30.4 \%$ of children did not consume the sachets adequately (of these, $84.0 \%$ did not like the MNP flavor).

Jack et al. (2012) [17]

Adherence: $93.3 \%$ of eligible children used MNP; the median number of MNP sachets consumed per month per child was 23.8 (range, 0-30).

Acceptability: No data given

Inayati et al. (2012) [15] Adherence: The proportion of children who consumed MNP daily was higher in the intensive nutrition education + MNP group than in the non-intensive nutrition education + MNP group (83.0\% vs $62.0 \%)$.

Acceptability: The main reasons given for not regularly consuming MNP included: perceived bitter taste of foods when mixed with MNP, monotonous taste when consumed daily, and occasionally forgetting to add MNP supplement to the lunch of a mildly wasted child. However, the majority of caregivers stated that they regularly added the MNP to the child's meal, but the child several times refused to consume it (data not shown).

Sampaio et al. (2012)

[7]

Adherence: The mean percentage of consumption, in days, of the entire contents of the sachets was $95.7 \%(S D=4.9)$ in the test group supplemented with MNP with zinc, and $96.4 \%$ $(S D=6.2)$ in the control group supplemented with MNP without zinc. Acceptability: No data given

Avula et al. (2011) [13] Adherence: No data given. Acceptability: No data given.

Bilukha et al. (2011) [14]

Kounnavong et al. (2011) [18] receiving MNP.
Adherence: Over $90.0 \%$ of children in each of the surveys from 2008 to 2010 were reported to currently consume MNP. Acceptability: $40.0 \%$ of caregivers reported changes to food after mixing it with MNP.In 2010,80.0 \% to $85.0 \%$ of caregivers reported perceived positive changes in children's health after

Adherence: All children in the twice-weekly group consumed two sachets of MNP per week. In the daily group, $72.7 \%$ of children consumed five or more sachets per week and $43.6 \%$ consumed all seven sachets per week for all 24 weeks.

Acceptability: $42.1 \%$ of mothers reported that MNP changed the colour of their children's food and $43.9 \%$ reported that it had an unpleasant smell or taste. However, some mothers mixed the MNP in liquids such as juice or milk. Many of the mothers felt that the MNP had increased their child's appetite (31.7\%) and playfulness (48.4\%).
Side effects: No data given.

Side effects: No data given.

Side effects: No data given.

Side effects: No data given.

Side effects: In this qualitative study, two of the five health workers said that there were some complaints from mothers regarding instances of diarrhoea; when MNP were administered, the children started losing weight. No data shown for the control group.

Side effects: The percentage of total of caregivers that reported any perceived negative health effects (diarrhoea, vomiting, constipation, etc.) attributed to multiple micronutrients was $11.6 \%$ in 2008, $5.6 \%$ in 2009, and $2.9 \%$ in 2010. This study had no control group.

Side effects: There were no significant differences in reports of illness (diarrhoea or cough) among the control, daily, and twice weekly groups $(32.7 \%, 39.1 \%$, and $34.2 \%$, respectively; $p=0.587$ ). 
Table 3 Summary of results regarding adherence to and acceptability and side effects of home fortification with multiple micronutrients in powder (MNP) (Continued)

\begin{tabular}{ll}
\hline Tripp et al. (2011) [23] & Adherence: No data given. \\
& Acceptability: MNP sachets were found to be acceptable and \\
& beneficial by mothers. Mothers said that MNP were easy to use, \\
& and several liked that the product had no taste or smell and \\
& did not change the taste of the food. Almost all mothers, regardless \\
& of the product they used, reported some increase in appetite or weight \\
& gain in their child (data not shown).
\end{tabular}

Jefferds et al. (2010) [22]

Lundeen et al. (2010) [19]

Rosado et al. (2010) [12]

Geltman et al. (2009) [11]

Adu-Afarwuah et al. (2008) [21]

Ip et al. (2007) [16]
Adherence: At midway (at 2 weeks of 1 month-study), observations of sachets in 24 households showed an average of 15 sachets used per child per household (range, 5 to 25). Five families reportedgiving away MNP to children living in other households or older children taking and consuming MNP without permission.

Acceptability: MNP's acceptability was high and most families reported that the children ate food with MNP without problems. Perceived positive effects observed in children: increased appetite and improvements in immunity, strength, activity levels, and weight gain (data not shown).

Adherence: Adherence was high. Average consumption of 45 of the 60 sachets provided; $39.0 \%$ of the children consumed all 60 sachets. Acceptability: $67.0 \%$ of caregivers reported that they liked using MNP, $73.0 \%$ reported that the MNP was easy to use, and $57.0 \%$ reported an improvement in their children's appetite.

Adherence: $84.6 \%$ (95\% Cl, $71.9 \%-97.2 \%)$ of children in the MNP group completed $80.0 \%$ of treatment dose (adequate adherence) and $71.0 \%(95 \% \mathrm{Cl}, 57.7 \%-84.4 \%)$ in this group completed the 4 months of treatment.

Acceptability: In this study the MNP treatment had the lowest acceptability. In this group, $6.4 \%(95 \% \mathrm{Cl}, 5.5-7.2)$ of children had trouble taking the treatment and $7.4 \%(95 \% \mathrm{Cl}, 6.5-8.4)$ disliked the treatment.

Adherence: High adherence (5 to 7 sachets consumed per week) ranged from $30.0 \%$ to $46.0 \%$ in the group supplemented with MNP. Acceptability: $12.0 \%$ of caregivers in the MNP group reported concerns about using a new product, $14.0 \%$ reported concerns about safety of the product for infants, and $17.0 \%$ reported difficulty in integrating administration of the supplement into a daily routine.

Adherence: At 12 months, median adherence $(95 \% \mathrm{Cl})$ to treatment in the MNP group was $85.8 \%$ (82.3-90.0). This adherence was determined as the percentage of scheduled days on which the supplement was added to the child's food.

Acceptability: In the MNP group, $96.9 \%$ of mothers liked giving the supplements to their children, $99.0 \%$ of mothers believed that consumption of the supplements benefited their children's health, $89.6 \%$ of mothers said that the child easily accepted food mixed feeding the child the supplement, and $100.0 \%$ of them had a good impression of the supplement.

Adherence: On average, children in the flexible 4-months group consumed $98.0 \%$ of prescribed sachets. The flexible 3-months group consumed an average of $93.0 \%$ and the daily 2-months group consumed $88.0 \%$. The proportion of children who consumed all prescribed sachets was $86.4 \%, 58.4 \%$, and $13.5 \%$ in the flexible 4-months, flexible 3-months, and daily 2-months groups, respectively. Acceptability: Most mothers reported changes in their child's behaviour (increased appetite and higher levels of activity and playfulness) after using MNP. MNPs were found to mix easily with food and had 'no' or 'mild' effects on the colour, taste, and smell of foods to which they were added. Almost all mothers preferred flexible administration over daily schedule (data not shown). with the supplement, $95.9 \%$ of mothers did not have major problems
Side effects: Several mothers reported diarrhoea in their children at the start of the study (data not shown).

Side effects: Infrequently mentioned by some caregivers were initial adjustments to MNP, including diarrhoea, softer stool, dark stool, and vomiting.

Side effects: Among participants in the intervention group, $32.0 \%$ of caretakers reported diarrhoea on 3 or more days during the 2-month intervention, $29.0 \%$ reported constipation, $9.0 \%$ reported vomiting, $4.0 \%$ reported an allergic reaction. No data shown for control group. Authors comment that these data must be cautiously interpreted because diarrhoea and other forms of gastrointestinal upset are quite common among young children in the Kyrgyz Republic.

Side effects: In the MNP group, the proportion of children experiencing any adverse event (allergies, infections, or viral diseases) was $10.9 \%$. In other groups this proportion was $4.3 \%$ (iron supplement), $5.4 \%$ (fortified food), $7.0 \%$ (zinc and iron and acid ascorbic fortified water), and $4.9 \%$ (iron and folic acid supplement).

Side effects: The main side effects in the MNP group were: constipation (15.0\% versus $26 \%$ in iron drops group; $p=0.14)$; diarrhoea (11.0\% versus $12 \%$ in iron drops group; $p=0.85)$, and vomiting ( $5.6 \%$ versus $8.8 \%$ in iron drops group; $p=0.51)$.

Side effects: No significant side effects were reported (data not shown).

Side effects: No data given. 
Table 3 Summary of results regarding adherence to and acceptability and side effects of home fortification with multiple micronutrients in powder (MNP) (Continued)

\begin{tabular}{|c|c|c|}
\hline Menon et al. (2007) [9] & $\begin{array}{l}\text { Adherence: An estimated mean } 57.6 \text { of the planned } 60 \text { sachets } \\
\text { were consumed (SD, 4.9; range, 27-60). } \\
\text { Acceptability: No data given. }\end{array}$ & Side effects: No data given. \\
\hline $\begin{array}{l}\text { Christofideset al. (2005) } \\
\text { [10] }\end{array}$ & $\begin{array}{l}\text { Adherence: Average adherence was } 59.6 \% \text { (SD, 27.7). Adherence } \\
\text { was determined by first calculating a score for each individual based } \\
\text { on the mean outcome over } 12 \text { monitoring visits, and then calculating } \\
\text { the overall mean percentage in the study population. } \\
\text { Acceptability: Mothers said that the MNP did not create any } \\
\text { appreciable change in colour, taste, or appearance of the } \\
\text { complementary food and that they were easy to use, although they } \\
\text { did have trouble remembering to give them daily. Participants agreed } \\
\text { that if MNP were to become a commercially marketed product, } \\
\text { they should be made available in their communities as an alternative } \\
\text { to iron syrup. }\end{array}$ & $\begin{array}{l}\text { Side effects: In the MNP group, the main side } \\
\text { effects were diarrhoea ( } 28.6 \% \text { versus } 33.9 \% \text { in } \\
\text { the placebo group; RR, } 1.09 ; 95 \% \mathrm{Cl}, 0.61-1.97 \text { ) } \\
\text { and vomiting ( } 8.2 \% \text { versus } 20.7 \% \text { in the } \\
\text { placebo group; RR, } 0.57 ; 95 \% \mathrm{Cl}, 0.23-1.39 \text { ). }\end{array}$ \\
\hline
\end{tabular}

$C$ confidence interval, IRR incidence rate ratio, $O R$ odds ratio, $R R$ relative risk, $S D$ standard deviation

children adopt flexible or non-daily administration model because it has greater adherence by children and caregivers and thus it is more effective and produce haematological effects similar to daily model.

Only one study, conducted by Geltmann et al. concluded that MNP had poor adherence, ranging from $30 \%$ to $45 \%$. It is necessary to remember that this conclusion was based on a definition of adequate adherence as the consumption of five to seven sachets per week, a level that was considered a satisfactory range in all of the other studies [11]. However, satisfactory acceptability was hindered by several factors including inappropriate use of the sachets. In some studies, mothers reported refusal of MNP by children because of changes in the taste of food. MNP is formulated not to alter the organoleptic characteristics of food. It is possible that lack of knowledge led some mothers to use the MNP improperly, for example by mixing it with a liquid food, which is not recommended.

It is known that effectiveness of MNP depends of caregivers to be motivated to offer sachets MNP for children properly and without interruption. In this regard, additional efforts could be made to increase adherence and acceptability of the intervention. For example, high mineral concentrations in MNP sachets can be perceived by the taste; thus, careful attention must be given to the supplements' sensory characteristics during the development process to minimize cases of rejection and to increase adherence to intervention. In addition, additional efforts should be planned in providing information and training to caregivers on appropriate use of MNP sachets since type of food used to mix them can affect its taste and consequently its acceptability.

One study cited the need for MNP to be mixed with food as a barrier to its use given the food situation in some of the countries in which these strategies have been implemented [23]. This study demanded public policies for food availability and distribution. As an alternative approach to address these issues, the Ministry of Health in Brazil developed the "NutriSUS" program, using fortification with MNP in young children attending day-care centres, in a sustainable and multisector strategy integrated with the cash transfer program "Bolsa Família." [26].

Some studies reported that a lack of knowledge and experience with MNP generated concerns among caregivers about its use and safety [11, 22]. It is possible that these problems related to the product distribution model and the monitoring of children who participated in intervention, problems that could be resolved through training directed at health professionals and a greater dialogue between professionals and caregivers to address possible doubts and encourage caregivers about the importance of MNP in promoting health of their children. Furthermore, the reported concern and uncertainty of participants about the use of MNP is normal considering it is a new product. In the study conducted by Geltman et al. the mothers who completed the intervention had the greatest understanding about the importance of vitamins and minerals for their children [11].

The main side effects cited in these studies were diarrhoea, vomiting, and constipation, ranging 3-32 \% of participants. These problems were more prevalent in the early days of MNP use. However, it must be cautiously interpreted when considering the possible side effects of MNP such as diarrhoea or other gastrointestinal diseases common in young children.

In a recent study by Soofi et al. in a malaria-endemic region of Pakistan with a stunting prevalence of $42 \%$ among children under 5 years of age, the authors found strong evidence of an increase in the proportion of days with diarrhoea and an increase in bloody diarrhoea in the groups receiving MNP [20, 27]. That study found that MNP had a modest effect on micronutrient deficiencies, and very little effect on growth $(p=0 \cdot 0017)[20]$. 
Another concern discussed in one study [23] is the need to mix MNP in semi-solid food because such food is not always available in low-income countries. The lack of knowledge and experience of professionals and caregivers in the use of MNP, the lack of availability of MNP, and its cost were also considered limitations in another study [22].

Despite of the described limitations, factors such as practicality of use increase in children's appetite, weight gain, and increased activity level, among others, contributed to the high acceptability of MNP. In most studies, participants expressed an interest in continuing MNP use and recommended it to other mothers, which leads us to believe in the potential success of future interventions of home fortification with MNP.

Given these findings, the authors recommend that despite the demonstrated effect of MNP in preventing iron deficiency anaemia, future studies on home fortification with MNP should pay special attention to the definitions and strategies for monitoring adherence and acceptability . This evaluation should account for issues affecting adherence and acceptability of MNPs, highlighting once again the need to direct strategies to the particular characteristics of the target population. Acceptability rates for MNPs have generally been above $83 \%$ in studies in developing countries, although rates are somewhat lower in studies performed in developed countries such as Canada (60\%) [ 1]. Because the use of the MNP requires their addition to foods suitable for young children, the home fortification strategy offers an opportunity to promote healthy complementary feeding, further improving the benefits of fortification [6]. However, it is likely that increased adherence to the use of MNP could result in greater impact on child health outcomes in future studies. Both adherence and acceptability can be increased when providing better guidance to caregivers and integration with the actions already performed by the healthcare team [6].

\section{Conclusions}

This systematic review suggests that home fortification of complementary feeding with MNP has good adherence and acceptability. However, both adherence and acceptability could be increased with adjustments in the distribution model, such as better guidance to caregivers, and in MNP administration frequency. Special attention is necessary when monitoring MNP use in malnourished populations with a high incidence of diarrhoea. Additionally, more studies are needed examining the efficacy of MNP related to adherence and acceptability to compare the positive and negative aspects of various intervention models, for the success of future programs and public policies.

\section{Ethics approval and consent to participate}

Not applicable. This review was reported in accordance with the PRISMA (Preferred Reporting Items for Systematic Reviews and Meta-Analyses) statement.

\section{Abbreviations}

MNP: multiple micronutrients in powder.

\section{Competing interest}

The authors declare that they have no competing interests.

\section{Authors' contributions}

SFB contributed to the selection of studies, data analysis and data interpretation, and to drafting the initial version of the manuscript. MAC developed the study design and protocol, and contributed to study selection, data interpretation, and to drafting and critical review of the manuscript. Both authors read and approved the final manuscript.

\section{Acknowledgements}

SF Barros was supported by a scholarship for scientific initiation from the São Paulo State Research Foundation (FAPESP, No 2013/12968-0). MA Cardoso is supported by the Brazilian National Counsel of Technological and Scientific Development, CNPq (Grant nos. 308308/2013-1; 552747/2011-4).

FAPESP and CNPq had no role in the design, analysis or writing of this article.

Received: 14 April 2015 Accepted: 23 March 2016

Published online: 07 April 2016

\section{References}

1. De-Regil LM, Suchdev PS, Vist GE, Walleser S, Peña-Rosas JP. Home fortification of foods with multiple micronutrient powders for health and nutrition in children under two years of age (Review). Cochrane Review Journal. 2013:8:112-201.

2. United Nations Children's Fund: Delivering essential micronutrients-Iron. http://www.unicef.org/nutrition/23964_iron.html (2003). Accessed 6 Apr 2016.

3. World Health Organization: Iron Deficiency Anaemia- Assessment, Prevention, and Control. A guide for programme managers. Geneva: World Health Organization; 2001.

4. World Health Organization. Use of multiple micronutrient powders for home fortification of foods consumed by infants and children 6-23 months of age. Geneva: World Health Organization; 2011.

5. Zlotkin SH, Schauer C, Christofides A, Sharieff W, Tondeur MC. Micronutrient sprinkles to control childhood anaemia. PLoS Medicine. 2005;2:e1.

6. Cardoso MA, Augusto RA, Bortolini GA, Oliveira CSM, Tietzman DC, Sequeira LAS, et al. Effect of providing multiple micronutrientes in poder through primary healthcare on anemia in young Brazilian children: a multicenter pragmatic controlled trial. PLoS One. 2016;11:e0151097.

7. Sampaio DLB, Mattos PD, Ribeiro TCM, Leite MEQ, Cole CR, Ribeiro HC. Suplementação de zinco e outros micronutrientes através do uso de sprinkles: impacto na ocorrência de doença diarreica e infecções respiratórias em crianças institucionalizadas. J Pedriatr. 2013;89:286-93.

8. Huamán-Espino L, Aparco JP, Nuñez-Robles E, Gonzáles E, Pillaca J, Tristán PM. Consumo de suplementos com multimicronutrientes Chispitas y anemia en niños de 6 a 35 meses: estudio transversal en el contexto de una intervención poblacional en Apurímac, Perú. Rev Peru Med Exp Salud Publica. 2012:29:314-23.

9. Menon P, Ruel MT, Loechl CU, Arimond M, Habicht JP, Pelto J, et al. Micronutrient Sprinkles reduce anemia among 9- to 24-mo-old children when delivered through an integrated health nutrition program in rural Haiti. J Nutr. 2007:137:1023-30.

10. Christofides A, Schauer C, Sharieff W, Zlotkin SH. Acceptability of micronutrient sprinkles: a new food-based approach for delivering iron to First Nations and Inuit children in Northern Canada. Chronic Dis Can Fall. 2005;26:114-20.

11. Geltman PL, Hironaka LK, Mehta SD, Padilla P, Rodrigues PMA, Alan FM, et al. Iron supplementation of low-income infants: a randomized clinical trial of adherence with ferrous fumarate sprinkles versus ferrous sulfate drops. J Pediatr. 2009;154:738-43. 
12. Rosado JL, Gonzalez KE, Caamano MC, Garcia OP, Preciado R, Odio M. Efficacy of different strategies to treat anemia in children: a randomized clinical trial. Nutr J. 2010;9:40.

13. Avula R, Frongillo EA, Arabi M, Sharma S, Schultink W. Enhancements to nutrition program in Indian integrated child development services increased growth and energy intake of children. J Nutr. 2010;141:680-84.

14. Bilukha O, Howard C, Wilkinson C, Bamrah S, Husain F. Effects of multimicronutrient home fortification on anemia and growth in Bhutanese refugee children. Food Nutr Bull. 2011;32:264-76.

15. Inayati DA, Scherbaum V, Purwestri RC, Wirawan NN, Suryantan JMD Hartono S, et al. Combined intensive nutrition education and micronutrient powder supplementation improved nutritional status of mildly wasted children on Nias Island, Indonesia. Asia Pac J Clin Nutr. 2012;21:361-73.

16. Ip H, Hyder SM, Haseen F, Rahman M, Zlotkin SH. Improved adherence and anaemia cure rates with flexible administration of micronutrient Sprinkles: a new public health approach to anaemia control. Eur J Clin Nutr. 2009;63:165-72.

17. Jack SJ, Ou K, Chea M, Chhin L, Devenish R, Dunbar M, et al. Effect of micronutrient sprinkles on reducing anemia: a cluster-randomized effectiveness trial. Arch Pediatr Adolesc Med. 2012;166:842-50.

18. Kounnavong S, Sunahara T, Mascie-Taylor CG, Hashizume M, Okumura J, Moji K, et al. Effect of daily versus weekly home fortification with multiple micronutrient powder on haemoglobin concentration of young children in a rural area, Lao People's Democratic Republic: a randomised trial. Nutr J. 2011;10:129.

19. Lundeen E, Schueth T, Toktobaev N, Zlotkin S, Hyder SM, Houser R. Daily use of Sprinkles micronutrient powder for 2 months reduces anemia among children 6 to 36 months of age in the Kyrgyz Republic: a clusterrandomized trial. Food Nutr Bull. 2010;31:446-60.

20. Soofi S, Cousens S, Iqbal SP, Akhund T, Khan J, Ahmed I, et al. Effect of provision of daily zinc and iron with several micronutrients on growth and morbidity among young children in Pakistan: a cluster-randomised trial. Lancet. 2013;382:29-40.

21. Adu-Afarwuah S, Lartey A, Brown KH, Zlotkin S, Briend A, Dewey KG. Home fortification of complementary foods with micronutrient supplements is well accepted and has positive effects on infant iron status in Ghana. Am J Clin Nutr. 2008;87:929-38.

22. Jefferds ME, Ogange L, Owuor M, Cruz K, Pearson B, Obure A, et al. Formative research exploring acceptability, utilization, and promotion in order to develop a micronutrient powder (Sprinkles) intervention among Luo families in western. Kenya Food Nutr Bull. 2010;31:S179-85.

23. Tripp K, Perrine CG, de Campos P, Knieriemen M, Hartz R, Ali F, et al. Formative research for the development of a market-based home fortification programme for young children in Niger. Matern Child Nutr. 2011:7:S382-95.

24. Hyder SMZ, Haseen F, Rahman M, Tondeur M, Zlotkin SH. Effect of daily versus once-weekly home fortification with micronutrient Sprinkles on hemoglobin and iron status among young children in rural Bangladesh. Food Nutrition Bulletin. 2007:28:156-64.

25. Sharieff W, Yin SA, Wu M, Yang Q, Schauer C, Tomlinson G, et al. Short-term daily or weekly administration of micronutrient Sprinkles has high compliance and does not cause iron overload in Chinese school children: a cluster randomized trial. Public Health Nutrition. 2006;9:336-44.

26. Ministério da Saúde no Brasil: Programa Saúde na Escola- PSE. http://dab.saude. gov.br/portaldab/pse.php?conteudo=nutrisus10.1186/s12889-016-2978- (2014). Accessed July 2014.

27. United Nations Children's Fund: Tracking Progress in Child and Maternal Nutrition- A survival and development priority. New York: United Nations Children's Fund (UNICEF); 2009.

\section{Submit your next manuscript to BioMed Central and we will help you at every step:}

- We accept pre-submission inquiries

- Our selector tool helps you to find the most relevant journal

- We provide round the clock customer support

- Convenient online submission

- Thorough peer review

- Inclusion in PubMed and all major indexing services

- Maximum visibility for your research

Submit your manuscript at www.biomedcentral.com/submit
Biomed Central 